\title{
A New Procedure of Concrete Mixture Designing
}

\author{
Milan KEKANOVIĆ, Eleonora KEKANOVIĆ
}

\begin{abstract}
Today's procedures of design mix of fresh concrete mixtures do not allow for water mass $\left(m_{w}\right)$ to be calculated exactly but through approximation methods which include calculating the type of aggregate, demanded consistency (slump concrete) and the largest aggregate grain $\left(D_{\max }\right)$. The other way demands that the water mass $\left(m_{w}\right)$ be read from a table which is based on the largest aggregate grain, aggregate origin and the demanded concrete of concrete subsidence. Hence, cement mass $\left(m_{c}\right)$ which is calculated based upon the aforementioned water mass $\left(m_{w}\right)$ is also approximate and, ultimately, the whole process is conducted in an approximate and not precise manner. According to the new method the authors are proposing, water mass is calculated precisely and in an exact manner in regard to the cement mass $\left(m_{c}\right)$ and the mass of all of the aggregate fractions $\left(m_{a}\right)$ in accordance with the projected or set granulometry. According to the new procedure, cement mass $(\mathrm{mc})$, water mass $(\mathrm{mw})$ and aggregate mass $(\mathrm{ma})$ are calculated simultaneously in regard to the projected or set concrete class ( $\mathrm{C} f \mathrm{ck}$, cyllfco, cube) and required concrete strength $f_{k, 28}$ through a set of three equations with cement mass $(\mathrm{mc})$, water mass $(\mathrm{mw})$ and aggregate mass $(\mathrm{ma})$ being the unknowns in these equations. This precise procedure is a necessity in a chase for better structures that could be seen standing in all their glory 1000 or 2000 years from now, as we are seeing Egyptian, Roman and Chinese and structures standing today.
\end{abstract}

Keywords: aggregate; cement; concrete; mixtures; water

\section{INTRODUCTION INTO THE SIGNIFICANCE AND PROBLEMS OF CONCRETE TECHNOLOGY}

Concrete is a material that is in the second place of production in the world today, right behind the water "production". If financial parameters and the cost of concrete are included, concrete is in the first place in the world. Of course, it is the main ingredient in most of the structures of vital importance to people. The goal is to make these structures as safe and long-lasting as possible, especially if the structures are of monumental size, importance or cost such as bridges, hydroelectric dams and the highest skyscrapers. All of this leads to a necessity for concrete production to be uplifted to a higher standard. Authors are of the opinion that the current method of design of concrete mixture is not adequately carried out and represented in the rule and guide books for concrete in Europe [2]. To be precise, the newest standard - EN 206 : 2013 A1 : 2016 [2] - does not define and recommend accurately enough the method of design of concrete mixture. The standard only prescribes the lowest cement masses $\left(m_{\mathrm{c}}\right)$ that are allowed in dependence on the concrete class and concrete exposure to the elements. Today's mixing and transportation of concrete is not suitable, especially if the distances are larger and the extreme temperatures of the surrounding air are reached. Concrete cannot be mixed for long as it will eventually subside to chemical processes such as hydration and water evaporation (the lowering of water percentage in the mixture). The final result of these processes is a change in concrete consistency which leads to poor embedding and processing of the concrete which is a subject for another paper. The authors are going to concentrate on the subject of method of design concrete mixture in a new method as proposed in this paper. The goal of the method is faster, more precise and exact projected concrete mixture and its desired consistency, from the lowest to the highest concrete classes. The reason for the birth of this method is predominantly the approximate method that has been and is being used in concrete mixture design. All of this is represented in the words of world renowned professor A. M. Neville [1]. All of us that are in the world of concrete technology and production have been taught and are still learning from the works of professor Neville. Professor A.M. Neville says that determining the mass of water in concrete is approximate [1], [3-6]. This means that the concrete mixture can widely vary in regard to its origin, kind and mass of aggregate and cement and in regard to the granulometry and required concrete class. Any change, even the slightest one, can result in drastic changes in concrete consistency, strength and quality. Being aware of the problem, the authors offer a new, exact method of concrete mixture design with innumerably higher amounts of precision in calculating the amounts of all concrete components, especially water mass $\left(m_{\mathrm{w}}\right)$ which is calculated simultaneously with the other components, aggregate and even in relation to the cement mass $\left(m_{\mathrm{c}}\right)$.

\subsection{Introduction into the Concrete Mixture Design}

There are a couple of procedures of concrete mixture designing in existence and application today, as shown in [1-6]. Normally, a concrete mixture is designed in regard to the required class of concrete. One of the most common procedures $[4,5]$ is based on Feret's Eq. (1) with regard to the type of aggregate, required consistency and the largest grain of aggregate. Of course, all of this is designed in a way to quantitative suit the mixing properties of water (water mass indicated with $\left(m_{\mathrm{w}}\right)$ ) with such a mixture.

$m_{\mathrm{w}}=\frac{k_{0}}{\sqrt[5]{D_{\max }}}$

$D_{\max }$ - the biggest oppening through which all of the fractions contained in the concrete mass have passed. As seen in Eq. (1), water mass $\left(m_{\mathrm{w}}\right)$ does not depend on the mass of any given fraction which is not known in that state. Also, it does not depend on the mass of concrete $\left(m_{\mathrm{c}}\right)$.

Given values of $k_{0}$ in (Tab. 1) are in regard to required consistency and aggregate type. Cement mass can be graphically determined in regard to the desired concrete stiffness $\left(f_{\mathrm{c}, 28}\right)$ and water cement factor $\left(m_{\mathrm{w}} / m_{\mathrm{c}}\right)$ :

$f_{\mathrm{k}, 28}=f_{\text {co, cube }}+c$ 
where: $f_{\text {co, cube }}$ - concrete cube pressure stiffness class, $c$ the increase of the concrete cube stiffness class (from 6 $\mathrm{MPa}$ to $12 \mathrm{MPa}$ ) - EN $206: 2013+\mathrm{A} 1: 2016$ [2].

Table $1 k_{0}$ according to Feret $[4,5$

\begin{tabular}{|l|c|c|c|}
\hline Consistency & $\begin{array}{c}\text { River sand } \\
\text { and river } \\
\text { gravel }\end{array}$ & $\begin{array}{c}\text { River sand and } \\
\text { crushed rock }\end{array}$ & $\begin{array}{c}\text { Crushed rock (large } \\
\text { and small aggregate) }\end{array}$ \\
\hline Rigid & $\leq 330$ & $\leq 330$ & $\leq 330$ \\
\hline Faintly plastic & $330-350$ & $350-375$ & $400-430$ \\
\hline Plastic & $350-370$ & $375-405$ & $430-460$ \\
\hline Liquid & $\geq 370$ & $\geq 405$ & $\geq 460$ \\
\hline
\end{tabular}

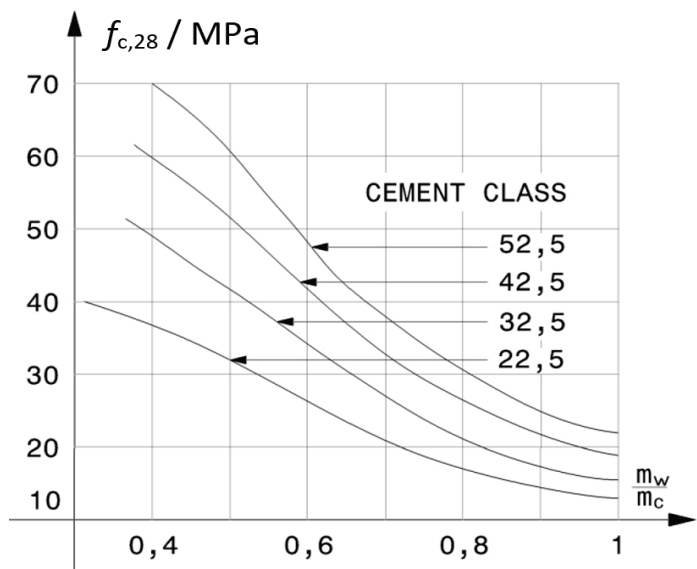

Figure 1 Graphic display of known curvatures of certain cement classes $[4,5]$

For the required concrete strength $f_{\text {co, cube }}$ to be reached, water-cement factor $\omega=m_{\mathrm{w}} / m_{\mathrm{c}}$ is calculated with the help of the graph illustrated in (Fig. 1). The water mass is known from Eq. (1) [5] which leads to the obvious $m_{\mathrm{c}}=m_{\mathrm{w}} / \omega$. There are other methods of determining the water mass illustrated by the authors A. M. Neville and J. J. Brooks [1] in the (Tab. 2) - The British method, and Tab. 3 - ACI method. All of today's methods of projecting the concrete mixtures start with the determination of water mass and subsequently the cement mass. The water mass is calculated approximately [3], based on the largest aggregate grain $D_{\max }$, the amount of concrete subsidence (slump concrete) and the origin of the aggregate (natural and crushed). Calculating in such an approximate way may lead to an unsatisfactory consistency of concrete. Also, higher classes of concrete have higher cement mass and subsequently the need for a higher water mass $\left(m_{\mathrm{w}}\right)$ which would not be provided if the calculations were conducted in such a manner. The increase of water mass $\left(m_{\mathrm{w}}\right)$ has a negative influence and reduces concrete strength.

Table 2 Approximate free water content required to give various levels of workability according to the 1997 British method [1]

\begin{tabular}{|c|c|c|c|c|c|c|}
\hline Aggregate & \multicolumn{6}{|c|}{ Water content $\mathrm{kg} / \mathrm{m}^{3}$ for } \\
\hline \multirow{2}{*}{$\begin{array}{c}\text { Max. size / } \\
\text { mm }\end{array}$} & \multirow{2}{*}{ Type } & $\begin{array}{c}\text { Slump / } \\
\mathrm{mm}\end{array}$ & $0-10$ & $\begin{array}{c}10- \\
30\end{array}$ & $\begin{array}{c}30- \\
60\end{array}$ & $\begin{array}{l}60- \\
180\end{array}$ \\
\hline & & Webe / s & $>12$ & $6-12$ & $3-6$ & $0-3$ \\
\hline \multirow{2}{*}{10} & Uncrushed & & 150 & 180 & 205 & 225 \\
\hline & Crushed & & 180 & 205 & 230 & 250 \\
\hline \multirow{2}{*}{20} & Uncrushed & & 135 & 160 & 180 & 195 \\
\hline & Crushed & & 170 & 190 & 210 & 225 \\
\hline \multirow{2}{*}{40} & Uncrushed & & 115 & 140 & 160 & 175 \\
\hline & Crushed & & 155 & 175 & 190 & 205 \\
\hline
\end{tabular}

There is also a solution to calculating the water mass $\left(m_{\mathrm{w}}\right)$ in concrete, which was provided by the author $\mathrm{M}$. Collepardi [5] in (Tab. 4). This solution, as do the others, implies that the water mass is calculated approximately. The following calculation of the cement mass is the same as before, $m_{\mathrm{c}}=m_{\mathrm{w}} / \omega$.

Table 3 Approximate requirements for mixing water and air content for different workability and nominal maximum sizes of aggregates according to $\mathrm{ACl}$ 211.191 (Reapproved 2002) [1]

\begin{tabular}{|c|c|c|c|c|c|c|c|c|}
\hline $\begin{array}{l}\text { Workability } \\
\text { or air content }\end{array}$ & \multicolumn{8}{|c|}{ Aggregate max. size / mm } \\
\hline \multirow{3}{*}{ Slump } & 10 & 12,5 & 20 & 25 & 40 & 50 & 70 & 150 \\
\hline & \multicolumn{8}{|c|}{ Non - air - entrained concrete } \\
\hline & \multicolumn{8}{|c|}{$\begin{array}{l}\text { Water content } / \mathrm{kg} / \mathrm{m}^{3} \text {, of concrete for indicated } \\
\text { maximum aggregate size }\end{array}$} \\
\hline $30-50 \mathrm{~mm}$ & 205 & 200 & 185 & 180 & 160 & 155 & 145 & 125 \\
\hline $80-100 \mathrm{~mm}$ & 225 & 215 & 200 & 195 & 175 & 170 & 160 & 140 \\
\hline $150-180 \mathrm{~mm}$ & 240 & 230 & 210 & 205 & 185 & 180 & 170 & - \\
\hline $\begin{array}{c}\text { Approximate } \\
\text { entrapped air } \\
\text { content, per } \\
\text { cent }\end{array}$ & 3 & 2,5 & 2 & 1,5 & 1 & 0,5 & 0,3 & 0,2 \\
\hline
\end{tabular}

Table 4 Approximate free water content required to give various levels of workability - the values of water in the table should be increased by $10 \mathrm{~kg} / \mathrm{m}^{3}$ when the aggregate is crushed and decreased by $10 \mathrm{~kg} / \mathrm{m}^{3}$ when the aggregate is natural [5]

\begin{tabular}{|c|c|c|c|c|c|}
\hline \multirow{2}{*}{$\begin{array}{c}D_{\max } \\
/ \mathrm{mm}\end{array}$} & \multicolumn{5}{|c|}{ Mixing water $/ \mathrm{kg} / \mathrm{m}^{3}$, at a slump / mm, of } \\
\cline { 2 - 6 } & $0-40$ & $50-90$ & $100-150$ & $160-200$ & $\geq 210$ \\
\hline 8 & 195 & 210 & 230 & 250 & 255 \\
\hline 20 & 180 & 195 & 215 & 225 & 230 \\
\hline 40 & 155 & 170 & 190 & 200 & 210 \\
\hline 50 & 145 & 160 & 180 & 190 & 195 \\
\hline 80 & 135 & 150 & 170 & 180 & 185 \\
\hline 100 & 120 & 135 & 150 & 160 & 165 \\
\hline
\end{tabular}

\subsection{Introductory Formulas}

The cement mass $\left(m_{\mathrm{c}}\right)$ does not need to be calculated by using the graph in Fig. 1 but can be exactly calculated in regard to the water-cement factor through the form of Feret's formula written in Eq. (4) which was obtained as an advancement of Eq. (3):

$$
f_{\mathrm{k}, 28}=\frac{k}{\left(1+\omega \cdot \frac{\gamma_{\mathrm{s}, \mathrm{c}}}{\gamma_{\mathrm{s}, \mathrm{w}}}\right)^{2}}
$$

where $k$ is the coefficient in regard to the class of cement. The Eq. (4) is given below:

$$
\frac{m_{\mathrm{w}}}{m_{\mathrm{c}}}=\frac{\gamma_{\mathrm{s}, \mathrm{w}}}{\gamma_{\mathrm{s}, \mathrm{c}}} \cdot\left(\sqrt{\frac{k}{f_{\mathrm{k}, 28}}}-1\right)
$$

with the condition $\sqrt{\frac{k}{f_{\mathrm{c}, 28}}}>1$. Mass of the additive $\left(m_{\mathrm{ad}}\right)$ is given in percentage in regard to the cement mass $\left(m_{\mathrm{c}}\right)$ according to Eq. (5):

$m_{\mathrm{ad}}=m_{\mathrm{c}} \cdot p_{\mathrm{ad}}$

Where $p_{\text {ad }}$ represents the quantity of the additive in percentage.

In regard to the required consistency, there is always an amount of trapped air $\left(V_{\mathrm{p}}\right)$ (from 1 to $3 \%$ ) that is stuck in the phase of concrete manufacturing. 
According to Eq. (9), the only thing remaining after determining the volumes and masses of the cement, water and additive is to determine the volume of the aggregate component $\left(V_{\mathrm{a}}\right)$. That volume takes from $55 \%$ up to even $75 \%$ of the total fresh concrete volume $\left(V_{\mathrm{co}, \text { fr }}\right)$. If the mass of a particular component $(m)$ and the specific mass $\left(\gamma_{\mathrm{s}}\right)$ are known, absolute volume $(V)$ of that particular component can be calculated from the equation:

$V=\frac{m}{\gamma_{\mathrm{s}}}$

\subsection{Calculating the Mass of Aggregate $\left(m_{\mathrm{a}}\right)$}

According to the previous presentation, the fresh concrete volume $\left(V_{\mathrm{co}}, \mathrm{fr}\right)$ can be calculated from the following expression:

$V_{\mathrm{co}, \mathrm{fr}}=1=V_{\mathrm{a}}+V_{\mathrm{c}}+V_{\mathrm{w}}+V_{\mathrm{ad}}+V_{\mathrm{p}}$

where: $V_{\mathrm{a}}$ - absolute volume of aggregate without pores and cavities between aggregate grains; $V_{\mathrm{c}}$ - absolute volume of aggregate without pores and cavities between aggregate grains; $V_{\mathrm{w}}$ - absolute volume of water; $V_{\mathrm{ad}}$ - absolute volume of additive; $V_{\mathrm{p}}$ - trapped air.

According to the Eq. (6), the volumes of components can be expressed in the following fashion:

$$
\frac{m_{\mathrm{co}, \mathrm{fr}}}{\gamma_{\mathrm{co}, \mathrm{fr}}}=1=\frac{m_{\mathrm{a}}}{\gamma_{\mathrm{v}, \mathrm{a}}}+\frac{m_{\mathrm{c}}}{\gamma_{\mathrm{s}, \mathrm{c}}}+\frac{m_{w}}{\gamma_{\mathrm{s}, \mathrm{w}}}+\frac{m_{\mathrm{ad}}}{\gamma_{\mathrm{s}, \mathrm{ad}}}+V_{\mathrm{p}}
$$

where: $m_{\mathrm{co}, \text { fr }}$ - concrete mass in fresh state; $\gamma_{\mathrm{co}, \text { fr }}$ - density of fresh concrete; $\gamma_{\mathrm{v}, \mathrm{a}}$-aggregate density; $\gamma_{\mathrm{s}, \mathrm{c}}$-specific weight of concrete; $\gamma_{\mathrm{s}, \mathrm{w}}$-specific weight of water; $\gamma_{\mathrm{s} \text {, ad }}$ specific weight of additives; $V_{\mathrm{p}}$ - volume of air that remains in the concrete after installation.

Where the designation $\gamma_{\mathrm{v}}$ a implies the volume mass of the aggregate. The aggregate mass $\left(m_{\mathrm{a}}\right)$ is the only unknown and can be directly calculated using the Eq. (9):

$m_{\mathrm{a}}=\gamma_{\mathrm{v}, \mathrm{a}} \cdot\left(1-\left(\frac{m_{\mathrm{c}}}{\gamma_{\mathrm{s}, \mathrm{c}}}+\frac{m_{w}}{\gamma_{\mathrm{s}, \mathrm{w}}}+\frac{m_{\mathrm{ad}}}{\gamma_{\mathrm{s}, \mathrm{ad}}}+V_{\mathrm{p}}\right)\right)$

The calculated aggregate mass is the mass of aggregate in a completely dry state. This implies that the eventual aggregate moisture must be included into the concrete production in a specific way of lowering the calculated water by the amount of the water placed around the aggregate.

Conversely, the aggregate mass must be increased by the same mass of water which is inside the aggregate. Special care is needed when dealing with $0,1 / 4 \mathrm{~mm}$ fractions.

\section{DESIGNING CONCRETE MIXTURES WITH A NEW PROCEDURE}

The integral procedure of designing new concrete mixtures entails setting linear equations depending on the linear dependence of the following components of fresh concrete: water, cement and aggregate. Masses of these individual components can be directly derived from these equations, as well as $m_{\mathrm{c}}^{*}, m_{\mathrm{w}}^{*}$ and $m_{\mathrm{a}}^{*}$. These three linear equations with three unknowns are:

$$
\begin{aligned}
& m_{\mathrm{a}}=\gamma_{\mathrm{v}, \mathrm{a}} \cdot\left(1-\left(\frac{m_{\mathrm{c}}}{\gamma_{\mathrm{s}, \mathrm{c}}}+\frac{m_{w}}{\gamma_{\mathrm{s}, \mathrm{w}}}+\frac{m_{\mathrm{ad}}}{\gamma_{\mathrm{s}, \mathrm{ad}}}+V_{\mathrm{p}}\right)\right) \\
& m_{\mathrm{c}}=\frac{m_{\mathrm{w}}}{\frac{\gamma_{\mathrm{s}, \mathrm{w}}}{\gamma_{\mathrm{s}, \mathrm{c}}} \cdot\left(\sqrt{\frac{k}{f_{\mathrm{k}, 28}}}-1\right)} \\
& m_{\mathrm{w}}=\left(\sum_{1}^{n} \Delta_{\mathrm{p}_{i}} \cdot \Delta_{\mathrm{w}_{i}}\right) \cdot m_{\mathrm{a}}+k_{\mathrm{w}} \cdot m_{\mathrm{c}}
\end{aligned}
$$

Linear Eq. (9) with $m_{a}$ being the unknown is derived from the basic linear Eq. (7) and Eq. (8) which expresses volumes of individual components in one unit of fresh concrete $\left(\gamma_{\mathrm{co}, \mathrm{fr}}\right)$.

Linear Eq. (10) with $\mathrm{m}_{\mathrm{c}}$ being the unknown is derived from the Feret's Eq. (3). Linear Eq. (11) with $m_{\mathrm{w}}$ being the unknown is derived from calculating the water mass in regard to the granulometric percentage participation of each individual fraction $\left(\Delta_{\mathrm{p}_{i}}\right)$ The smaller the aggregate grains inside a particular volume and aggregate mass are, the bigger the specific aggregate surface $\left(S=\mathrm{cm}^{2} / \mathrm{g}\right)$ is. A bigger specific surface of aggregate entails a greater amount of water for drenching of the surface in the need of a water film at the surface. The need for water of an individual fraction in regard to the specific surface and needed mountability and design (in regard to consistency) is expressed through the factor $\left(\Delta_{\mathrm{w}_{i}}\right)$. The sum $\left(\sum_{1}^{n} \Delta_{\mathrm{p}_{i}} \cdot \Delta_{\mathrm{w}_{i}}\right)$ multiplied with aggregate mass $\left(m_{\mathrm{a}}\right)$ gives an amount needed for the easier movement of aggregate through the fresh concrete. The second part of the equation $\left(k_{\mathrm{w}} \cdot m_{\mathrm{c}}\right)$ represents the water mass which is dosed in regard to the cement mass. The bigger the cement mass inside the mixture, the higher the demand for water because a higher degree of fresh concrete motion is needed in regard to the required consistency.

The system of linear equations displayed before could be analyzed easier by forming the system determinant $\left(D_{\mathrm{s}}\right)$. The starting point is the assumption that there are now additives (plastificators, aerant, accelerator, antifreeze, etc) in the first step. This essentially means that there is no substraction of the water which means that $k_{\mathrm{ad}}$ is implied. The system determinant is displayed below:

$$
D_{\mathrm{s}}=\mid \begin{gathered}
\frac{1}{\gamma_{\mathrm{v}, \mathrm{a}}} \frac{1}{\gamma_{\mathrm{s}, \mathrm{c}}}+\frac{1}{\gamma_{\mathrm{s}, \mathrm{w}}} \frac{p_{\mathrm{ad}}}{\gamma_{\mathrm{s}, \mathrm{ad}}} \\
\frac{\gamma_{\mathrm{s}, \mathrm{w}}}{\gamma_{\mathrm{s}, \mathrm{c}}} \cdot\left(\sqrt{\frac{k}{f_{\mathrm{k}, 28}}}-1\right)-1 \\
\sum_{1}^{n} 4_{\mathrm{p}_{i}} \cdot \Delta_{\mathrm{w}_{i}} k_{\mathrm{w}}-1
\end{gathered}
$$


Having simplification in mind, the best procedure is to introduce the following expressions:

$a_{1}=\frac{1}{\gamma_{\mathrm{v}, \mathrm{a}}}$

$a_{3}=\sum_{1}^{n} \Delta_{\mathrm{p}_{i}} \cdot \Delta_{\mathrm{w}_{i}}$

$b_{1}=\frac{1}{\gamma_{\mathrm{s}, \mathrm{c}}}+\frac{p_{\mathrm{ad}}}{\gamma_{\mathrm{s}, \mathrm{ad}}}$

$b_{2}=\frac{\gamma_{\mathrm{s}, \mathrm{w}}}{\gamma_{\mathrm{s}, \mathrm{c}}} \cdot\left(\sqrt{\frac{k}{f_{\mathrm{k}, 28}}}-1\right)$

$b_{3}=k_{\mathrm{w}}$

$c_{1}=\frac{1}{\gamma_{\mathrm{s}, \mathrm{w}}}$

and in knowing $k_{\mathrm{ad}}=1$, we get:

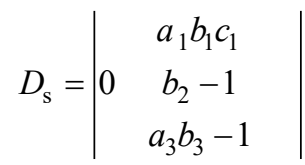

The method the authors are offering, in addition to advantages of precise calculations of all of the concrete constituents, has a mathematical drawback. Solving three equations with three unknowns is an easy task at the first glance, but this set of equations consists of a lot of constants that are represented as coefficients which means that calculating the unknowns is very hard without appropriate software. This resulted in the creation of an algorithm which was the base of the software that was created in order to make this method easily applicable.

Solving the system determinant results in the following result:

$D_{\mathrm{s}}=a_{1} \cdot\left(b_{3}-b_{2}\right)-a_{3} \cdot\left(b_{1}+b_{2} \cdot c_{1}\right)$

Determinants of individual unknowns $\left(\left(D_{m_{\mathrm{a}}}\right),\left(D_{m_{\mathrm{c}}}\right),\left(D_{m_{\mathrm{W}}}\right)\right)$ should be formed, too:

$$
\begin{aligned}
D_{m_{\mathrm{a}}} & =\left|\begin{array}{c}
1-V_{1} b_{1} c_{1} \\
0 \\
b_{2}-1 \\
a_{3} b_{3}-1
\end{array}\right| \begin{array}{cc}
a_{1} 1-V_{p} c_{1} \\
D_{m_{\mathrm{c}}}
\end{array}=\left|\begin{array}{ccc}
0 & 0 & -1 \\
a_{3} & 0 & -1
\end{array}\right| \\
D_{m_{\mathrm{w}}} & =\left|\begin{array}{ccc}
0 & a_{1} b_{1} 1-V_{p} & \\
a_{3} b_{3} & b_{2} & 0
\end{array}\right|
\end{aligned}
$$

Now, $m_{\mathrm{a}}, m_{\mathrm{c}}$ and $m_{\mathrm{w}}$ can be determined, after putting the right expressions Eq. (13) - Eq. (18) inside Eq. (21) Eq. (23), and having in mind $x=\frac{D_{m_{\mathrm{x}}}}{D_{\mathrm{s}}}$ we finally get:

$$
\begin{aligned}
& \left(1-V_{p}\right) \cdot\left(k_{\mathrm{w}}-\frac{\gamma_{\mathrm{s}, \mathrm{w}}}{\gamma_{\mathrm{s}, \mathrm{c}}} \cdot\left(\sqrt{\frac{k}{f_{\mathrm{k}, 28}}}-1\right)\right) \\
& m_{\mathrm{a}}=\frac{1}{\frac{1}{\gamma_{\mathrm{v}, \mathrm{a}}}\left(k_{\mathrm{w}}-\frac{\gamma_{\mathrm{s}, \mathrm{w}}}{\gamma_{\mathrm{s}, \mathrm{c}}} \cdot\left(\sqrt{\frac{k}{f_{\mathrm{k}, 28}}}-1\right)\right) \cdot \sum_{i=1}^{n} 4_{\mathrm{p}} \cdot \Delta_{\mathrm{w}_{i}}\left(\left(\frac{1}{\gamma_{\mathrm{s}, \mathrm{c}}}+\frac{p_{\mathrm{ad}}}{\gamma_{\mathrm{s}, \mathrm{ad}}}\right)+\left(\frac{\gamma_{\mathrm{s}, \mathrm{w}}}{\gamma_{\mathrm{s}, \mathrm{c}}} \cdot\left(\sqrt{\frac{k}{f_{\mathrm{k}, 28}}}-1\right)-\frac{1}{\gamma_{\mathrm{s}, \mathrm{w}}}\right)\right)} \\
& \left(1-V_{p}\right) \cdot \sum_{i=1}^{n} 4_{\mathrm{p}_{i}} \cdot \Delta_{\mathrm{w}_{i}}
\end{aligned}
$$

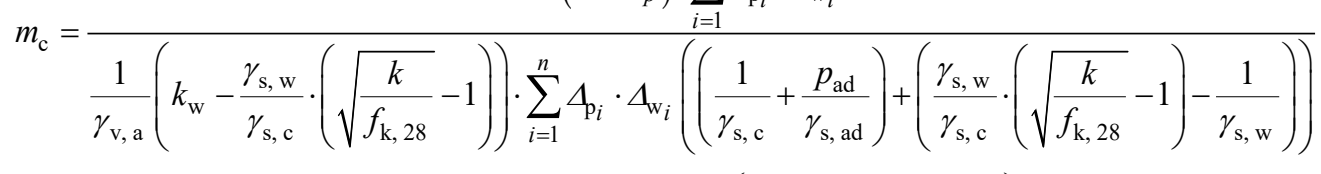

$$
\begin{aligned}
& -\left(1-V_{p}\right) \cdot \sum_{i=1}^{n} 4_{i} \cdot \Delta_{\mathrm{w}_{i}} \cdot\left(\frac{\gamma_{\mathrm{s}, \mathrm{w}}}{\gamma_{\mathrm{s}, \mathrm{c}}} \cdot\left(\sqrt{\frac{k}{f_{\mathrm{k}, 28}}}-1\right)\right) \\
& m_{\mathrm{w}}=\frac{1}{\frac{1}{\gamma_{\mathrm{v}, \mathrm{a}}}\left(k_{\mathrm{w}}-\frac{\gamma_{\mathrm{s}, \mathrm{w}}}{\gamma_{\mathrm{s}, \mathrm{c}}} \cdot\left(\sqrt{\frac{k}{f_{\mathrm{k}, 28}}}-1\right)\right) \cdot \sum_{i=1}^{n} \Delta_{\mathrm{p}_{i}} \cdot \Delta_{\mathrm{w}_{i}}\left(\left(\frac{1}{\gamma_{\mathrm{s}, \mathrm{c}}}+\frac{p_{\mathrm{ad}}}{\gamma_{\mathrm{s}, \mathrm{ad}}}\right)+\left(\frac{\gamma_{\mathrm{s}, \mathrm{w}}}{\gamma_{\mathrm{s}, \mathrm{c}}} \cdot\left(\sqrt{\frac{k}{f_{\mathrm{k}, 28}}}-1\right)-\frac{1}{\gamma_{\mathrm{s}, \mathrm{w}}}\right)\right)}
\end{aligned}
$$
cement mass $\left(m_{\mathrm{c}}^{*}\right)$ and aggregate mass $\left(m_{\mathrm{a}}^{*}\right)$ are attained:

$m_{\mathrm{w}}^{*}=m_{\mathrm{w}} \cdot k_{\mathrm{ad}}$

$$
\begin{aligned}
& m_{\mathrm{c}}^{*}=\frac{m_{\mathrm{w}}^{*}}{b_{2}} \\
& m_{\mathrm{a}}=\gamma_{\mathrm{v}, \mathrm{a}} \cdot\left(1-\left(\frac{m_{\mathrm{c}}}{\gamma_{\mathrm{s}, \mathrm{c}}}+\frac{m_{\mathrm{w}}}{\gamma_{\mathrm{s}, \mathrm{w}}}+\frac{m_{\mathrm{ad}}}{\gamma_{\mathrm{s}, \mathrm{ad}}}+V_{\mathrm{p}}\right)\right)
\end{aligned}
$$

These attained formulas are fairly complex and too long for manual calculation, hence a program for calculation was developed. It provides a very fast way of 
attaining these masses (water, cement and aggregate mass, with the addition of additive mass), if additive is present. The only thing that is needed is importation of values that characterize individual materials. The rest is left for the program to calculate.

\subsection{Examples of Tested Concrete Mixture Designs}

The following example is a calculation of a mixture of a concrete (class $C$ 35/45) with a projected cube hardness $f_{\mathrm{k}, 28}=45+8=53 \mathrm{MPa} \mathrm{MPa}$, where $c=8 \mathrm{MPa}$ the increase of the concrete cube stiffness class (from $6 \mathrm{MPa}$ to 12 MPa) - EN $206: 2013+$ A1 : 2016 [2]. The applied cement is of class $-k=42,5$. The consistency should be of liquid form so that the concrete could be applied with the help of a pump. The aggregate is made up of three fractions (river aggregate) with the following sizes: 0,09/4 $\mathrm{mm}, 4 / 8 \mathrm{~mm}$ and $8 / 16 \mathrm{~mm}$. A part of the following text will include the proposed method of fresh concrete mixture calculation with the help of a computer program with the name of "Concrete mix design". This program was developed at the Faculty of Civil Engineering in Subotica [9], University of Novi Sad [10]. Input parameters and component characteristics of the concrete are given in (Tab. 5). Values of $\Delta_{w_{i}}$ and the value $k_{\mathrm{w}}$ are given and based upon a number of examinations in a duration of 28 days (assigned consistency and stiffness are controlled in regard to the assigned class of concrete and size and percentage of individual fractions).

Table 5 Example - Input parameters and components of concrete

\begin{tabular}{|c|c|}
\hline$\Delta_{p_{0,09 / 4}}=36 \%$ & $\begin{array}{l}\text { percentage of the fraction consisting of grains from } \\
0,09 \text { to } 4 \mathrm{~mm} \text { in size with } 36 \% \text { in granulometry }\end{array}$ \\
\hline$\Delta_{p_{4 / 8}}=24 \%$ & $\begin{array}{l}\text { percentage of the fraction consisting of grains from } \\
4 \text { to } 8 \mathrm{~mm} \text { in size with } 24 \% \text { in granulometry }\end{array}$ \\
\hline$\Delta_{p_{8 / 16}}=40 \%$ & $\begin{array}{l}\text { percentage of the fraction consisting of grains from } \\
8 \text { to } 16 \mathrm{~mm} \text { in size with } 40 \% \text { in granulometry }\end{array}$ \\
\hline$\Delta_{w_{0,09 / 4}}=0,195$ & $\begin{array}{l}\text { coefficient which determines the amount of water } \\
\text { needed for the } 0,09 / 4 \mathrm{~mm} \text { fraction }\end{array}$ \\
\hline$\Delta_{w_{4 / 8}}=0,054$ & $\begin{array}{l}\text { coefficient which determines the amount of water } \\
\text { needed for the } 4 \text { / } 8 \mathrm{~mm} \text { fraction }\end{array}$ \\
\hline$\Delta_{w_{8 / 16}}=0,017$ & $\begin{array}{l}\text { coefficient which determines the amount of water } \\
\text { needed for the } 8 / 16 \mathrm{~mm} \text { fraction }\end{array}$ \\
\hline$V_{\mathrm{p}}=0,01$ & $\begin{array}{l}\text { percentage amount of air that is trapped in the } \\
\text { process of fresh concrete applying }\end{array}$ \\
\hline$k=320$ & coefficient in the function of cement class $-42,5$ \\
\hline$p_{\text {ad }}=0,0000001$ & $\begin{array}{l}\text { percentage of the additive in regard to the cement } \\
\text { mass }\end{array}$ \\
\hline$f_{\mathrm{k}, 28}=53 \mathrm{MPa}$ & $\begin{array}{l}\text { projected and required stiffness resistance of the } \\
\text { concrete to the pressure (at day 28) }\end{array}$ \\
\hline$k_{\mathrm{w}}=0,18$ & $\begin{array}{l}\text { coefficient which determines the amount of water } \\
\text { needed for cement mixing }\end{array}$ \\
\hline$k_{\mathrm{ad}}=1$ & $\begin{array}{l}\text { coefficient which determines the percentage } \\
\text { reduction of water (in this case plasticizer acts as } \\
\text { additive which means there is no water reduction - } \\
\text { if } k_{\text {ad }}=0,95 \text { then percentage of water reduction is } \\
5 \%)\end{array}$ \\
\hline$\gamma_{\mathrm{v}, \mathrm{a}}=2650 \mathrm{~kg} / \mathrm{m}^{3}$ & volume mass of aggregate \\
\hline$\gamma_{\mathrm{s}, \mathrm{c}}=3000 \mathrm{~kg} / \mathrm{m}^{3}$ & specific mass of cement \\
\hline$\gamma_{\mathrm{s}, \mathrm{w}}=1000 \mathrm{~kg} / \mathrm{m}^{3}$ & specific mass of water \\
\hline$\gamma_{\mathrm{s}, \text { ad }}=1000 \mathrm{~kg} / \mathrm{m}^{3}$ & $\begin{array}{l}\text { specific mass of additive, if there is some (this is } \\
\text { the typical value) }\end{array}$ \\
\hline
\end{tabular}

Author of this paper deems that it is necessary for a large number of concrete mixture designs for every concrete class and consistency, with different types of aggregates, to be tested and run through this new method. Statistics and Gauss's law, with assigned values of probability deviation from the real result, help determine values of $\Delta_{w_{i}}$ and $k_{\mathrm{w}}$ (Tab. 5). Authors of this paper have analyzed the natural aggregate (river aggregate) while projecting concrete mixtures Fig. 2, Fig. 3 and Fig. 4 in this particular example. The results for the particular type of aggregate yielded the values of coefficients which determine the amount of water needed for each fraction $\left(\Delta_{w_{i}}\right)$. Type and class of cement is CEM II/A-S 42,5R which provided the coefficient $k_{\mathrm{w}}$ that determines the amount of water needed for cement mixing. (Fig. 2) shows the recipe of concrete in the absence of superplasticizer. Coefficient $k_{\text {ad }}$ determines the percentage reduction of water in concrete mix because superplastificizer now acts as an additive. If $k_{\mathrm{ad}}=0$ then there is no superplasticizer additive which means there is no water reduction. This, in turn, means that the recipe given in (Fig. 2) needs a reduction to the value of water mass $\left(m_{\mathrm{w}}\right)$.

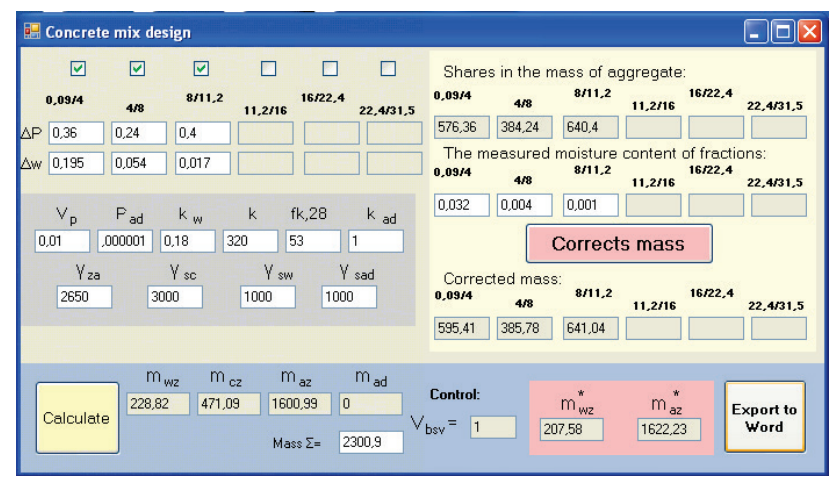

Figure 2 The program that provides values acquired by the way of a new method - example of $k_{\text {ad }}=1$ (no water reduction)

As mentioned before, the coefficient value of $k_{\mathrm{ad}}=$ 0,85 means there is a $15 \%$ of water reduction. The results with such a requirement are given in (Fig. 3).

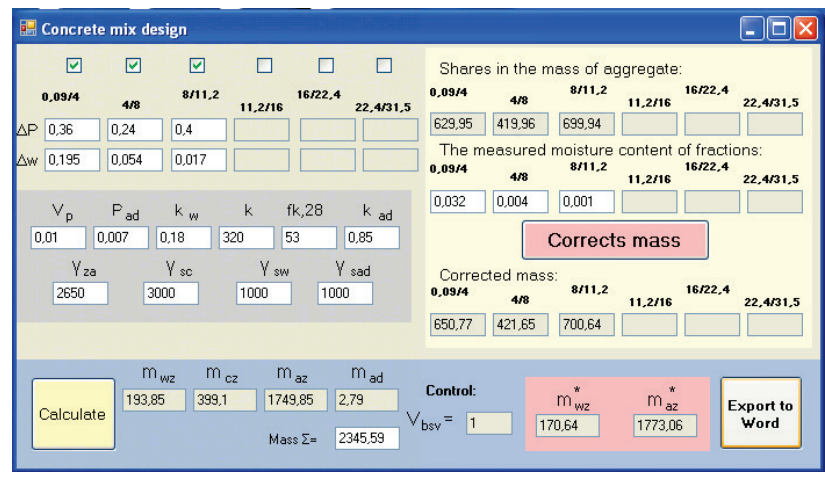

Figure 3 Concrete mixture designing run through the new method - example of $k_{\text {ad }}=0,85$ (with a water reduction of $15 \%$ )

By using a higher percentage of plasticizer $\left(p_{\mathrm{ad}}=0,01\right)$, water can be reduced up to $30 \%$ which means that $k_{\mathrm{ad}}=0,7$. Reduction of water in the mixture with retained consistency, integrity and viability would yield the same strength with a much smaller amount of cement, as can be seen in (Fig. 4). Such a reduction of water - with sustained consistency, mountability and processing ability - would result in the same stiffness with a significant lowering of the cement amount needed which can be easily observed in (Fig. 4). 


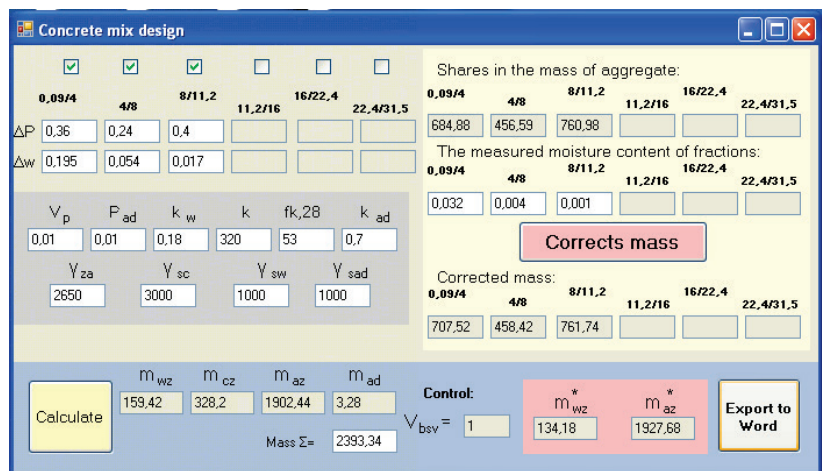

Figure 4 Concrete mixture designing run through the new method - example of $k_{\text {ad }}=0,7$ (with a water reduction of $30 \%$ )

Authors would also like to present some other possibilities of fresh concrete mixture modeling which the new method and software are providing. As has already been said a number of times, the new method offers an exact method of calculating the masses of all of the concrete components. It is very important to note that the water mass $m_{w}$ is directly influenced by the mass of every single grain of a particular aggregate fraction $\left(m_{\mathrm{a}}\right)$ and also by the cement mass $m_{\mathrm{c}}$. That can be easily shown in an example where there is a reduction of $2 \%$ of granulometric participation of the first fraction. This results in a granulometric participation of the first fraction $(0,09 / 4$ $\mathrm{mm}$ ) of $\Delta_{p_{0,09 / 4}}=34 \%$. The granulometric participation of the second fraction $(4 / 8 \mathrm{~mm})$ is $\Delta_{p_{4 / 8}}=25 \%$. The granulometric participation of the third fraction $(8 / 16 \mathrm{~mm})$ is, of course, $\Delta_{p_{8 / 16}}=41 \%$. (Fig. 5) shows a graphic attachment of a projected concrete mixture in the same conditions for the concrete class $\mathrm{C} 35 / 45$ with the required strength on the $28^{\text {th }}$ day $-f_{\mathrm{k}, 28}=45+8=53 \mathrm{MPa}$.

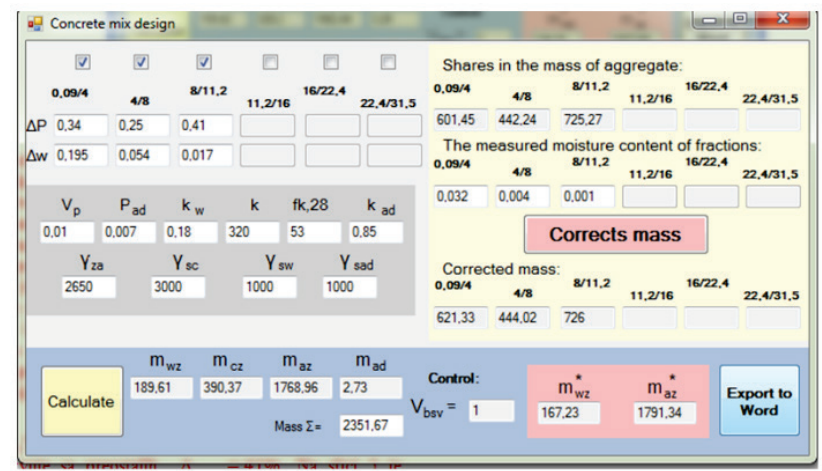

Figure $\mathbf{5}$ Concrete mixture designing run through the software - example with the value $k_{\mathrm{ad}}=0$ (with a water reduction of $15 \%$ ) - granulometry change as $\Delta_{p_{0,09 / 4}}=36-2=34 \%$

As can be seen from (Fig. 5), the water mass is reduced because the fraction $0,09 / 4 \mathrm{~mm}$ binds and needs the most water. By reducing water, the need for cement is automatically lessened while also keeping the same and projected strength of $f_{\mathrm{k}, 28}=45+8=53 \mathrm{MPa}$. It can also be seen that the software automatically calculates the corrected masses of water $\left(m_{w}^{*}\right)$ [8], and aggregate $\left(m_{\mathrm{a}}^{*}\right)$ [8] if the aggregate is moist while dosing it into the mixer.

\section{FUTURE GOALS ON THE ADVANCEMENT OF THE CONCRETE PRODUCTION TECHNOLOGY}

As the authors of the method, we are working to expand the application of the method onto the other types of concrete and mortar. Concrete is a material that interests us and we are working hard to improve it. This is the first paper we offer with the intention of improving the technology of concrete mixture designs. The second paper we are announcing on this occasion is the application of this new method with the help of patented mixers of new generation. This new generation mixer can be applied as stable with multiple vertical chambers and with a large capacity (several hundred $\mathrm{m}^{3} / \mathrm{h}$ ) where concrete components are dosed continually and uninterruptedly at one end. The other end would be an exit for the mixture which would be poured into the mobile mixers or concrete pumps.

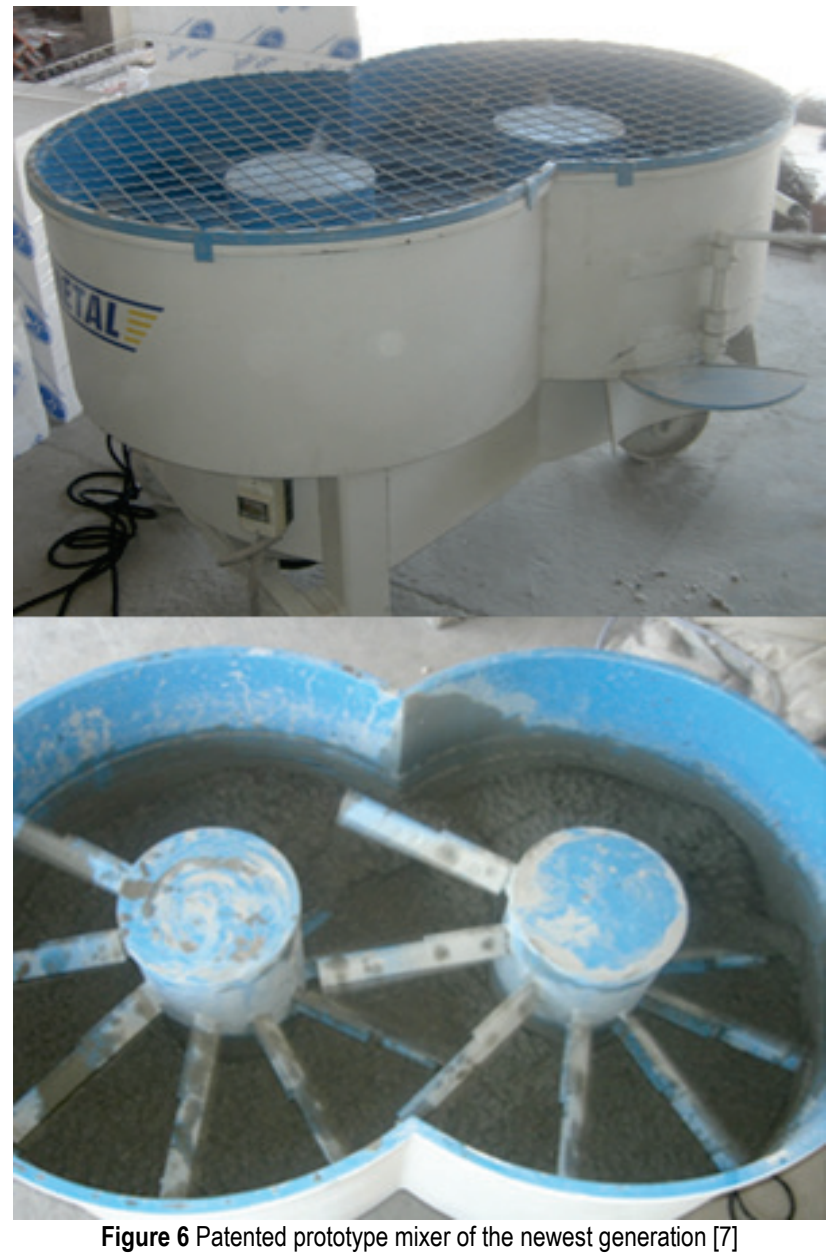

Also, this mixer could be mobile with the capacity of up to $25 \mathrm{~m}^{3}$ in the back of large trucks. The mixer is able to take in concrete components (cement and aggregate) in their raw form, with no former mixing, in its vertical chambers. The water would be dosed in a separate tank on the mixer. All of this would be done at the concrete plant. The mixer would drive to the construction sites without mixing. Dry mixing of aggregates, cement and superplasticizers can be started in order to achieve physical chemical activation of the cement. At the construction site, mixing would start with water dosing and within the shortest time of 5 minutes the required consistency of 
concrete from $\mathrm{F}^{\mathrm{A}}$ to $\mathrm{F} 6^{\mathrm{A}}$ is achieved and would be of very high quality - EN $206: 2013$ A1 : 2016 [2]. Concrete is a material that does not withstand long mixing due to the possibility of initiating chemical processes of hydration and changes in consistency. Concrete mixture must be mixed in the shortest possible time and incorporated in good quality in order to achieve the best possible quality concrete that will guarantee its existence after several hundred or more thousand years. The new generation of mixers represents the wish of the author to enhance the technology of concrete production.

\section{CONCLUSIONS}

This paper provides a new method of ordinary fresh concrete mixture designing. The method is based on three linear equations (Eq. (9), Eq. (10) and Eq. (11)) with three unknowns: cement mass $\left(m_{\mathrm{c}}\right)$, aggregate mass $\left(m_{\mathrm{a}}\right)$ and water mass $\left(m_{\mathrm{w}}\right)$. This way, mutually inclusive dependence of these unknowns provides a way of determining water mass $\left(m_{\mathrm{w}}\right)$, concerning several items, which are: aggregate mass of individual fractions $\left(m_{\mathrm{a}_{\mathrm{i}}}\right)$ and cement mass $\left(m_{\mathrm{c}}\right)$.

Aggregate, cement and water mass are determined from a set of completely new equations developed by the author of this paper: Eq. (24), Eq. (25) and Eq. (26), respectively. If superplasticizer is as an additive present in the mixture, the water mass correction is needed and it is accomplished through Eq. (27). Also, cement and aggregate mass corrections are needed which is accomplished through Eq. (28) and Eq. (29) [8]. The expressions in these equations are pretty complicated, thus a computer program "Concrete Mix Design" was developed for easier and quicker calculation. As authors, we very strongly feel that this method of accurate calculations of the masses of concrete components is very important in furthering the concrete technology. Also, it is important to note the fact that allows for every type of mixture for every concrete class to be designed according to the current standards [2] (EN $206: 2013+$ A1 : 2016) water mass $\left(m_{\mathrm{w}}\right)$ is simultaneously calculated as the other components are and is dependent on every single aggregate and cement grain. The principles this method is based on could be adapted for lightweight concretes, mortar, asphalt and mixtures that have epoxy as a binding agent. Also, as is obvious with everything in the computer world, software can be upgraded and expanded upon. It is possible to implement parameters of volume masses of several types of aggregate $\left(\gamma_{\mathrm{a}}\right)$ and specific masses of several types of cement $\left(\gamma_{\mathrm{s}, \mathrm{c}}\right)$ into the software.

We hope that this method of concrete mixture designing will be of use to technologists for concrete as well as institutes and researchers all over the world.

\section{Acknowledgements}

The work reported in this paper is a part of the investigation within the research project - III 42012 "Energy efficiency enhancement of building in Serbia and improvement of national regulative capacity for their certification", supported by the Ministry for Science and Technology, Republic of Serbia. This support is gratefully acknowledged.

\section{REFERENCES}

[1] Neville, A. M. \& Brooks, J. J. (2010). Concrete Technology, Second Edition, Pearson Education Limited, ISBN 978-0273-73219-8.

[2] EN 206:2013+A1:2016 [E], (2016).

[3] Kosmatka, S. H., Kerkhoff, B., \& Panarese, W. C. (2003). Design and Control of Concrete Mixtures, EB001, 14 ${ }^{\text {th }}$ edition, Portland Cement Association, Skokie, Illinois, USA.

[4] Grdić, Z. (2011). Tehnologija betona. Textbook, Niš, ISBN 978-86-80295-94-7 (in Serbian).

[5] Muravljov, M. (2010). Osnovi teorije i tehnologija betona. Textbook, Stylos Beograd, ISBN 978-86-395-0614-8 (in Serbian).

[6] Collepardi, M. (2010). The New Concrete. Grafiche Tintoretto, ISBN: 978-88-903-7772-3.

[7] Kekanovic, M. (2012). Patent No. 52156, Zavod za intelektualnu svojinu, Beograd, R. Srbija (in Serbian).

[8] Kekanović, M. (2019). The New Method of Calculation the Exact Weight of Wet Aggregates and Adjusted Weight of Water at a Rate and Production of Concrete. Tehnicki Vjesnik-Technical Gazette, 26(5). https://doi.org/10.17559/TV-20171227110951

[9] www.gf.uns.ac.rs

[10] www.uns.ac.rs

\section{Contact information:}

Milan KEKANOVIĆ, Associate Professor, PhD

(Corresponding author)

Faculty of Civil Engineering Subotica,

University of Novi Sad,

Kozaračka 2a, 24000 Subotica, Serbia

E-mail: kekec@gf.uns.ac.rs

Eleonora KEKANOVIĆ, Mathematician JP POSTA SRBIJE,

Prvomajska 2, 24000 Subotica, Serbia

E-mail: ekekanovic@jp.ptt.rs 